\title{
Getting Local Government Onboard: Prioritizing Decisions Rationally
}

\author{
Ellen Szarleta, Ph.D., J.D.. Director \\ Center for Urban and Regional Excellence \\ Indiana University Northwest \\ eszarlet@iun.edu
}

\begin{abstract}
The value of AHP to local government decision making processes is clear to those practicing MCDM methods. Local government, however, views such processes with skepticism and concern. The policy and political implications of the application rational decision making processes in local government must be understood before the method will take hold. Examining these implications also provides the foundation for a cultural change occurs supportive of AHP as a rational way of decision making.
\end{abstract}

\section{Proposal}

The value of AHP to local government decision-making processes is clear to those practicing MCDM methods. Local government, however, views such processes with skepticism and concern. The policy and political implications of the application rational decision-making processes in local government must be understood before the method will take hold.

Examining these implications also provides the foundation for a cultural change occurs supportive of AHP as a rational way of decision making. In this paper the costs and benefits of AHP are evaluated from the local government decision maker's perspective. The analysis then outlines an approach for expanding the toolbox beyond decision-making specialists. A case study of the application of AHP by local government is also provided. The paper will stimulate discussion of the application and dissemination of AHP in the local government sector.

Examining the issue of local government adoption of AHP techniques is the start of the conversation. AHP provides powerful tools for improving the efficiency and effectiveness of government but is not widely used at the local level. Communicating the value of AHP to local government decision makers requires an understanding, from the policy perspective, of the value of not using AHP. Over the course of the past 18 months the researcher has been involved in an initiative aimed at demonstrating the 
value of AHP to sustainable development decision-making processes at the local level. The public administration model currently used by local government is not compatible with the application of AHP. Thus, adoption is not complete, although interest remains. A careful review of wellaccepted models of public administration reveals points at which AHP meets with resistance.

The paper identifies this decision points, evaluates the present public administration model and its usefulness to rational decision making processes and proposes modifications that will improve the likelihood that AHP will be effectively used in the local government arena.

\section{References:}

Ngah, K., et. al., "A Proposed Model in Fundamental of Decision Making Process at Local Government Level," Asian Social Science, Vol 8, No.8, July 2012

Johnson, W.C., Public Administration: Policy, politics and practice, 1992.

Moynihan, D.R., "Managing for Results in State Government: Evaluating a Decade of Reform," Public Administration Review, January/February 2006.

Peters, B. Guy, et. al. "Governance Without Government? Rethinking Public Administration," Journal of Public Administration Research and Theory, April 1998. 